\title{
One week's holiday sun exposure induces expression of photoaging biomarkers
}

\author{
Aleksandra Lesiakㅁ, Michal Rogowski-Tylman ${ }^{1}$, Marian Danilewicz ${ }^{2}$, \\ Anna Wozniacka ${ }^{1}$, Joanna Narbutt ${ }^{1}$
}

${ }^{1}$ Department of Dermatology, Medical University of Lodz, Poland

${ }^{2}$ Department of Pathology, Medical University of Lodz, Poland

\begin{abstract}
Introduction. Skin aging is accompanied by the upregulation of the expression of various matrix metalloproteinases (MMPs). It was shown that exposure to ultraviolet radiation (UVR) may induce skin expression of MMPs and dysregulation of the transforming growth factor beta (TGF- $\beta$ )/Smad pathway. The aim of our study was to compare the effects of short holiday UVR exposure and lifetime UVR exposure, on the expression of MMP-8, TGF- $\beta 1$, and Smad2 in human skin biopsies.

Material and methods. Skin biopsies were taken from the outer upper arm of 15 elderly people with significant photoaging (mean age 64.1 years) (Group 1) and from 15 healthy young adult volunteers (mean age $24.1 \mathrm{y}$ ) who participated in a six-day sun holiday. Biopsies were taken twice: 24 hours before leaving for holiday (Group 2a) and 24 hours after returning (Group 2b). The expression of TGF- $\beta 1$, Smad2, and MMP- 8 was examined by immunochemistry and measured semiquantitatively by two independent pathologists.

Results. The mean expression of TGF- $\beta 1$ in dermal fibroblasts and keratinocytes in Group 1 and Group $2 \mathrm{~b}$ was significantly lower than in Group $2 \mathrm{a}(0.54 \% \pm 0.44 \%$ and $0.48 \% \pm 0.51 \%$ vs. $1.48 \% \pm 0.72 \%$, respectively). The percentage of Smad2 (+) cells in Group 1 and Group 2b was lower than in Group 2a $(2.13 \% \pm 1.39 \%$ and $1.81 \%$ $\pm 1.16 \%$ vs. $4.13 \% \pm 1.58 \%$, respectively). The MMP-8 expression in Group $2 \mathrm{~b}$ was $1.36 \% \pm 0.68 \%$ and was significantly higher than in Group $1(0.34 \% \pm 0.42 \%)$ and Group $2 \mathrm{a}$ in which the protein was not detected $(\mathrm{p}<0.001)$. Conclusions. We conclude that the decrease in the expression of TGF- $\beta 1$ and Smad2 is a persistent biomarker of skin photoaging, while the increased expression of MMP-8 in keratinocytes can be regarded as a marker of acute sun exposure. (Folia Histochem Cytobiol. 2016, Vol. 54, No. 1, 42-48)
\end{abstract}

Key words: photoaging; TGF- $\beta 1$; Smad2; MMP-8; short and long UVR exposure; IHC

\section{Introduction}

The extracellular matrix (ECM) is mainly composed of collagens type I and type III, elastic fibers, proteoglycans, and fibronectin. In skin exposed to UVR, the disorganization of collagen fibers, deposits of elastin, and decreased amounts of collagen I and III precursors are observed [1]. Matrix metalloproteinases (MMPs) are proteolytic enzymes with the ability to

\footnotetext{
Correspondence address: Assoc. Prof. A. Lesiak

Department of Dermatology

Medical University of Lodz

Plac Hallera 1, 90-647 Lodz, Poland

tel./fax: +48 $426867981,+48426884565$

e-mail: aleksandra.lesiak@umed.lodz.pl
}

degrade collagen, elastic fibers, and other proteins [2]. The overexpression of MMPs upon exposure of the skin to UVR is one of the important causes of photoaging and the development of skin cancers. In our study, it was shown that UVR mainly induces three metalloproteinases in the epidermis, namely, collagenase (MMP-1), 92-kD gelatinase (MMP-9), and stromelysin (MMP-3). These proteins are translocated through the basement membrane and may cause total degradation of skin collagen and promote skin aging [3]. Additionally, dysregulation of ECM glycoproteins such as laminin and the impairment of the proliferation of keratinocytes lead to disorganization of the dermal-epidermal junction. It was shown that even a single exposure to suberythemal UVR is sufficient to induce MMP-1 and MMP-9 expression in 
dermal fibroblasts. These observations are the reason why daily photoprotection in normal life should be strongly recommended [4].

In vitro studies have shown the role of transforming growth factor beta (TGF- $\beta$ ) in the synthesis of collagen [5]. In aging skin, there is a decreased expression of the gene encoding TGF- $\beta$ which results in lower collagen synthesis [6]. Skin exposure to UVR enhances this process via impairment of the TGF- $\beta$ / /Smad signaling pathway and ultimately results in the inhibition of the synthesis of procollagen I [7]. Most available studies on the subject have been performed in vitro or on animal models, and erythemal doses of UVR were used. There are only scarce data on the role of TGF- $\beta$ in naturally occurring photoaging in humans [8]. Still, the role of suberythemal UVR doses on molecular processes in skin and the development of photoaging in daily life has not yet been fully elucidated. The correlation between the type of solar exposure (time, intensity) and the initiation of the molecular mechanisms involved in photoaging has not been clearly resolved. We are not aware of studies of specific protein expression known to be biomarkers of photoaging. Thus, the aim of our study was to assess the influence of short holiday UVR exposure, as well as of lifetime UVR exposure, on the expression of metalloproteinase 8 , TGF- $\beta 1$ and Smad 2 in human skin in young adult and elderly subjects.

\section{Material and methods}

Subjects and material collection. The study involved 30 healthy Caucasian subjects. The study was approved by the Ethics Committee of the Medical University of Lodz, Poland, and each participant gave written informed consent to participate in the study. The material for the study consisted of skin biopsies taken from subjects divided into two groups. Group 1 included elderly people with clinically strongly photodamaged skin ( 7 women, 8 men, aged $64.1 \pm 5.4 \mathrm{y}$, mean $\pm \mathrm{SD}$; phototype II, $\mathrm{n}=7$, phototype III, $\mathrm{n}=8$ ). Group 2 consisted of 15 healthy young adult volunteers ( 7 women, 8 men, mean age $24.1 \pm 6.8 \mathrm{y}$; phototype II, $\mathrm{n}=6$, phototype III, $\mathrm{n}=9$ ), who participated in a six day-long sun holiday on Tenerife in the Canary Islands, Spain $\left(28^{\circ} \mathrm{N} 16^{\circ} \mathrm{W}\right)$ in March 2011. Subjects were recruited by the Dermatology Department of the Medical University of Lodz, Poland. The exclusion criteria were a history of skin disease (including skin cancer), the use of photosensitizing medication, and sunbed or holiday sun exposure within the previous 4 months. The volunteers were not given any instructions on sunscreen use, which was not monitored, in order to avoid any influence on their photoprotection habits. They were told to bring their own sunscreens as they normally would for a holiday. Participants had approximately 5 hours of sun exposure every day between 09:00 to 17:00 local time. Personal UVR exposure was monitored using wrist-worn SunSavers. These are electronic devices that record time-stamped erythemal exposure expressed as SED (standard erythema dose). Similar devices were also placed on an un-shaded location on the roof of one of the hotels to monitor ambient UVR exposure. Mean cumulative UVR dose for each participant from group 2 was 45 SED. In all the volunteers, $4 \mathrm{~mm}$ skin biopsies were taken to assess MMP-8, TGF- $\beta 1$, and Smad expression. In Group 1 , the skin specimens were taken once, while in Group 2, they were taken twice: 24 hours before leaving for Tenerife (Group 2a) and 24 hours after coming back (Group 2b). The skin biopsies were taken from outer part of arm in each participant of the study.

Immunochemistry. The expression of MMP-8, TGF- $\beta 1$, and Smad were examined by immunohistochemical technique. Skin biopsies were fixed in $4 \%$ neutralized formaldehyde and routinely processed into paraffin blocks. Paraffin sections were mounted onto SuperFrost slides, deparaffinized, then treated in a microwave oven in a solution of TRS (Target Retrieval Solution, DakoCytomation, Glostrup, Danemark), pH 6.0 for $30 \mathrm{~min}(360 \mathrm{~W} 2 \times 6 \mathrm{~min}, 180 \mathrm{~W} 2 \times 5 \mathrm{~min}, 90 \mathrm{~W}$ $2 \times 4 \mathrm{~min}$ ) and transferred to distilled water. Endogenous peroxidase activity was blocked by $0.3 \%$ hydrogen peroxide in distilled water for $30 \mathrm{~min}$, and then sections were rinsed with Tris-buffered saline (TBS, DakoCytomation) and incubated for $1 \mathrm{~h}$ with rabbit polyclonal anti-human antibodies: Smad2 (1:200; ab63576, Abcam, Cambridge, UK), TGF- $\beta 1$ (3 $\mu \mathrm{g} / \mathrm{mL}$, ab66043, Abcam) and MMP8 (1:200, ab78423, Abcam). Afterwards EnVision + System-HRP (DakoCytomation) prepared according to the manufacturer's instruction. Visualization was performed by incubating the sections in a solution of 3.3'-diaminobenzidine (DakoCytomation). After washing, the sections were counter-stained with hematoxylin and coverslipped. For each antibody and each sample negative control were processed. Negative controls were carried out by incubation in the absence of the primary antibody and always yielded negative results.

Semiquantitative evaluation of MMP-8 and TGF- $\beta$ immunoreactivity. In each specimen, the staining intensity of TGF- $\beta 1$ and MMP-8 was assessed semiquantitatively by two independent observers in 6-8 adjacent high-power fields and graded as 0 (staining not detectable), 1 (weak immunostaining), 2 (moderate immunostaining intensity), or 3 (strong staining). The mean grade was calculated by averaging the grades assigned by the two investigators and approximating the arithmetical mean to the nearest unity.

Morphometry of Smad2-immunoposistive cells. Histological morphometry was performed by means of an image analysis system consisting of a PC computer equipped with a Pentagram graphical tablet, Indeo Fast card (a true-color real-time 

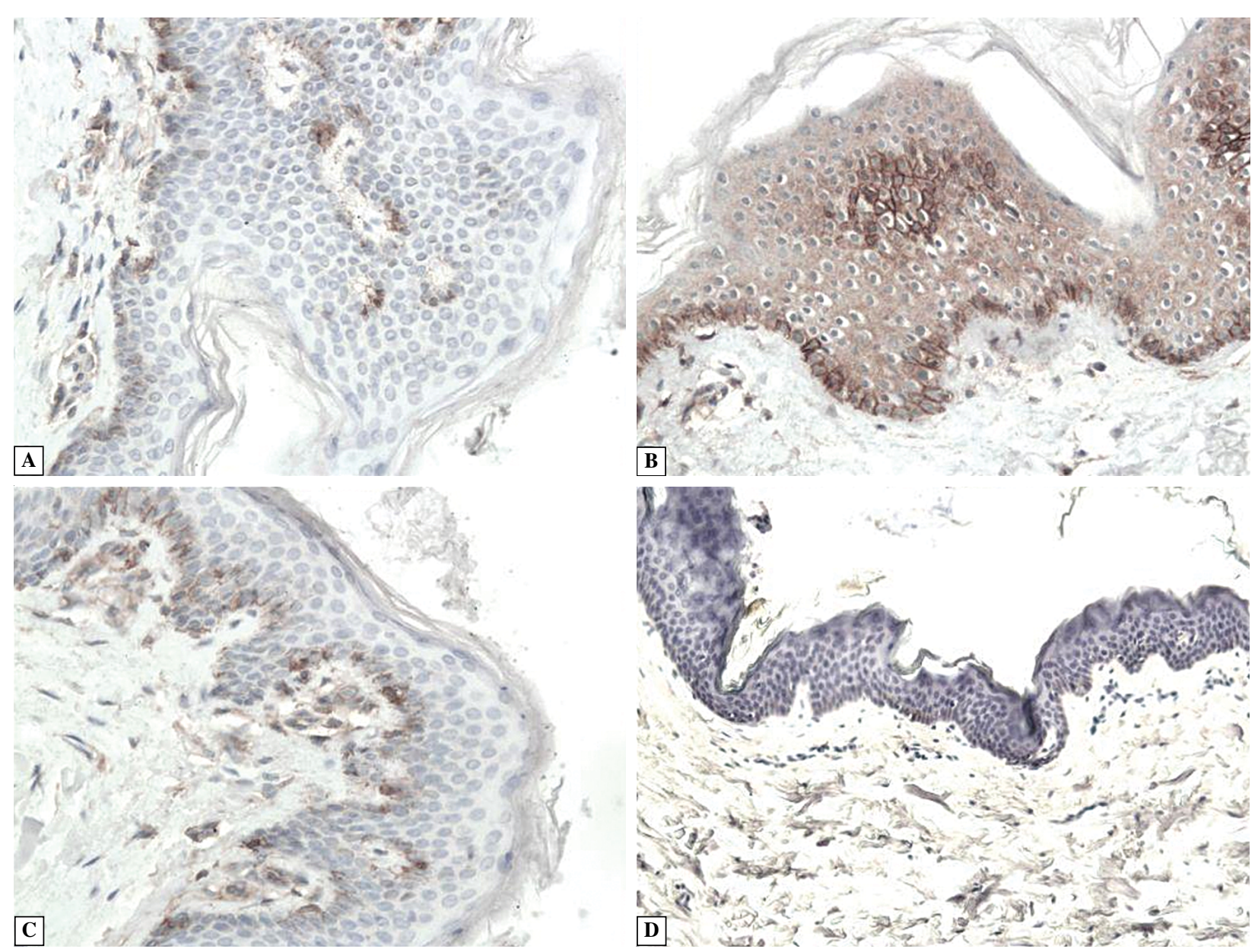

Figure 1. The immunoreactivity of transforming growth factor beta 1 (TGF- $\beta 1$ ) in skin biopsies. A. Cytoplasmic immunoreactivity is present in some keratinocytes of the basal layer of epidermis and few dermal fibroblasts in Group 1; B. Intense immunoexpression in keratinocytes of the basal layer and weak in other layers of epidermis in Group 2a; C. Weak immunoexpression in keratinocytes of the basal layer of epidermis in Group 2b; D. Negative control. Magnification $\times 100$

frame grabber), and color TV camera (Panasonic, Tokyo, Japan) coupled to a Carl Zeiss microscope (Carl Zeiss, Jena, Germany). This system was programmed (using MultiScan 8.08 software, produced by Computer Scanning Systems, Poland) to calculate the number of objects (semiautomatic function). The colored microscopic images were saved serially in the computer's memory, and quantitative examinations were then carried out. The percentage of immunopositive cells was estimated by semiautomatic counting of 100 cells in ten monitor fields $\left(0.029 \mathrm{~mm}^{2}\right.$ each $)$, so that, in each case, 1000 cells per biopsy were analyzed.

Statistical analysis. All values were expressed as means \pm SDs (standard deviation). The differences between groups were tested using Student's $t$-test for independent samples preceded by evaluation of normality and homogeneity of variances with Levene's test. Additionally, the Mann-Whitney $U$-test was used where appropriate. Correlation coefficients were calculated using the Spearman method. Results were considered statistically significant if $\mathrm{p}<0.05$.

\section{Results}

The results represent morphologic evaluation of skin biopsies obtained from the elderly subjects with photodamaged skin (Group 1) and from young adult subjects who spent a six day-long sun holiday (Group 2). In the Group 1, the skin specimens were taken once, while in Group 2, they were taken 24 hours before leaving for sun holidays (Group 2a) and 24 hours after coming back (Group 2b).

\section{The immunoreactivity of the studied proteins in the skin}

The cytoplasmic immunoexpression of TGF- $\beta 1$ was observed in keratinocytes and some dermal fibroblasts (Figure 1A-D). Cytoplasmic immunoreactivity was seen in some keratinocytes of the basal layer of epidermis and in few fibroblasts in Group 1 (Figure 1A), whereas intense immunoexpression was observed in keratinocytes of the basal layer and a weaker one in 

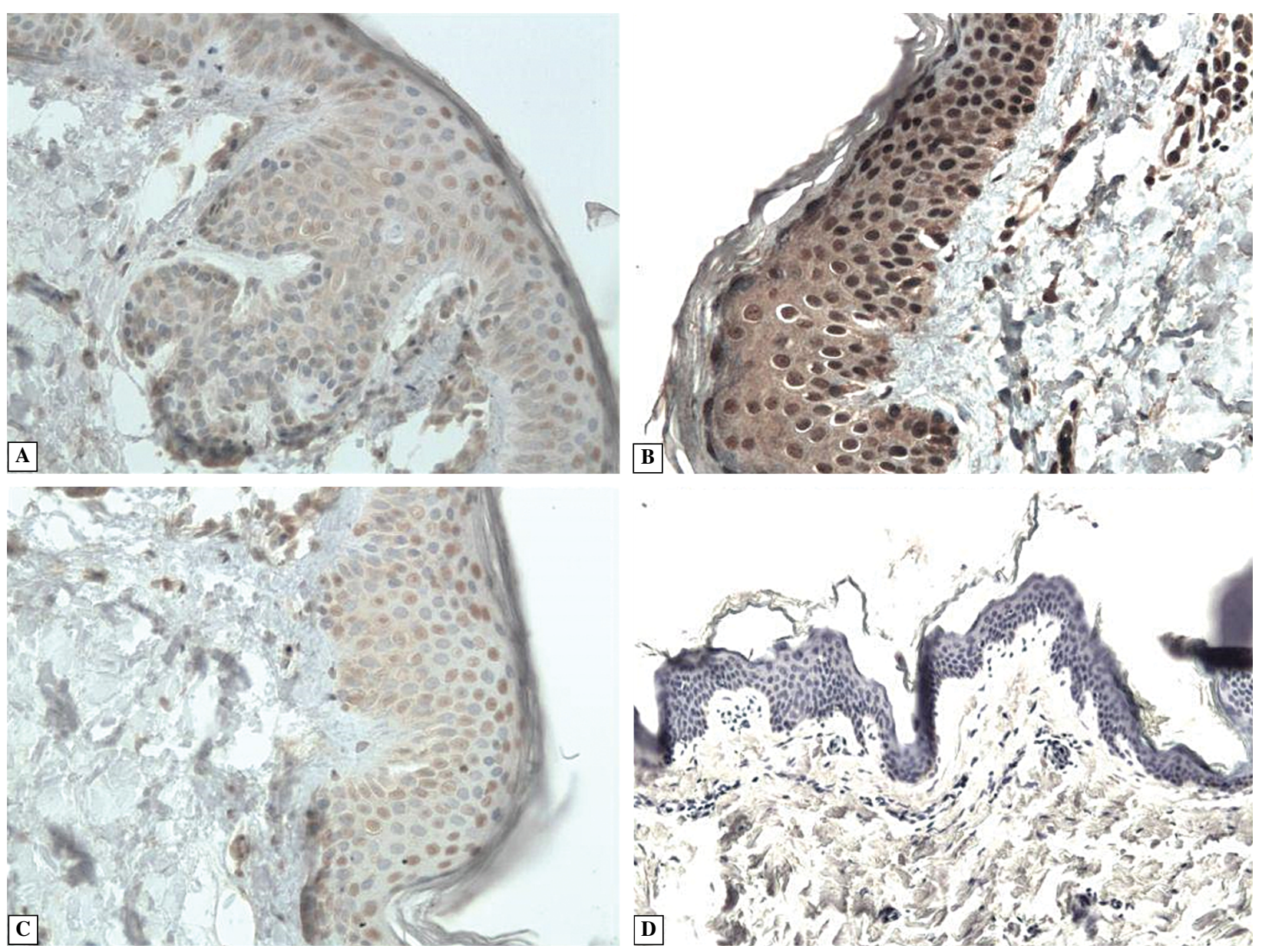

Figure 2. The immunoreactivity of Smad 2 in skin biopsies. A. Weak nuclear immunoexpression of Smad 2 in keratinocytes mainly of the basal layer of epidermis in Group 1; B. Strong immunoexpression in all layers of epidermis in Group 2a; C. Moderate immunoexpression in all layers of epidermis in Group 2b; D. Negative control. Magnification $\times 100$

other layers of epidermis in Group 2a (Figure 1B). Weak TGF- $\beta 1$ immunoexpression in keratinocytes of the basal layer of epidermis in group $2 \mathrm{~b}$ was noted (Figure 1C).

On the contrary, the immunoreactivity of Smad2 was observed in all non-keratinized layers of epidermis. It was mainly nuclear and rarely cytoplasmic (Figure 2A-D). Weak nuclear immunoexpression of Smad2 was found in keratinocytes mainly of the basal layer of epidermis in Group 1 (Figure 2A) and strong immunoexpression in all layers of epidermis in Group 2a (Figure 2B). Moderate immunoexpression in all layers of epidermis in Group 2b (Figure 2C) was seen.

The immunoreactivity of MMP-8 was noted in keratinocytes, few dermal fibroblasts and in some inflammatory cells (Figure 3A-D). This immunoexpression was weak in Group 1 (Figure 3A), negative in Group 2a (Figure 2B) and moderate in Group 2b (Figure 2C).

\section{The proportion of the immunoreactive cells in skin biopsies}

The mean percentage of TGF- $\beta 1$ immunoreactivity in skin biopsies in Group 1 and Group $2 \mathrm{~b}$ was significantly lower than in Group $2 \mathrm{a}(0.54 \% \pm 0.44 \%$ and $0.48 \%$ $\pm 0.51 \%$ vs. $1.48 \% \pm 0.72 \%$, respectively; Table 1$)$.

The percentage of Smad2 immunopositive cells in Group $2 \mathrm{~b}$ was $1.81 \% \pm 1.16 \%$, and was lower than before sun holiday (Group 2a: $4.13 \% \pm 1.58 \%$; $\mathrm{p}<0.002$; Table 1). In Group 1, the percentage of Smad 2 immunoreactive cells was $2.13 \% \pm 1.39 \%$, significantly lower than in Group 2a ( $p<0.008)$. There was no difference between Groups 1 and $2 b$ (Table 1).

The proportion of MMP-8 immunoreactivity in skin biopsies in Group 2b was $1.36 \% \pm 0.68 \%$, and was significantly higher than in Group 2a, in which the protein was not detected (Table 1). In Group 1 , MMP-8 expression was present in $0.34 \% \pm 0.42 \%$ of cells and was significantly higher than in Group 2a 

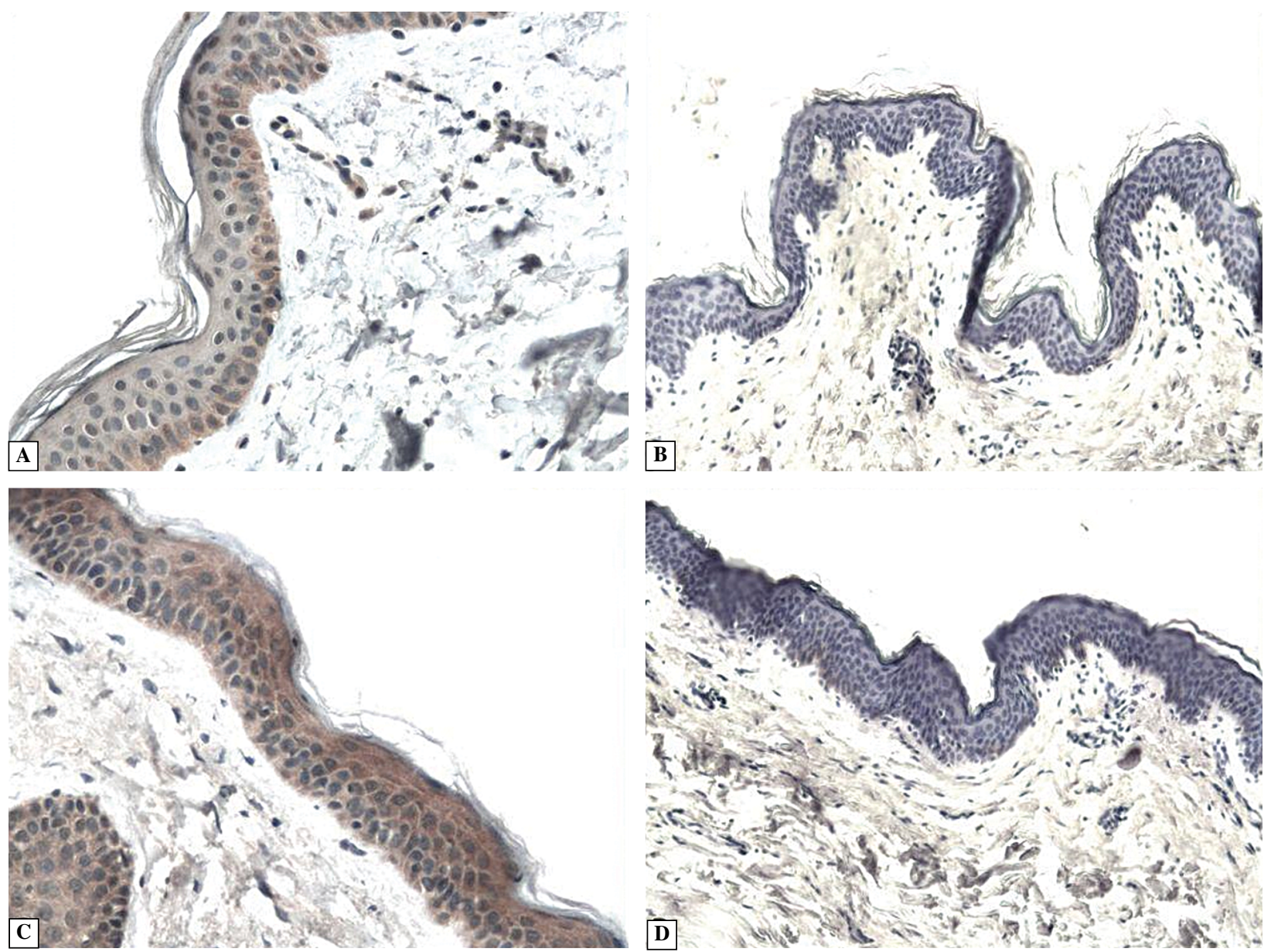

Figure 3. The immunoreactivity of matrix metalloproteinase 8 (MMP-8) in skin biopsies. A. Weak immunoexpression of MMP-8 in keratinocytes, few dermal fibroblasts, and in some inflammatory cells in Group 1; B. Negative immunoexpression in Group 2a; C. Moderate immunoexpression in keratinocytes and dermal fibroblasts in Group 2b; D. Negative control. Magnification $\times 100$

Table 1. The percentage of immunoreactive cells in skin biopsies

\begin{tabular}{|l|c|c|c|}
\hline & TGF- $\beta$ 1 & Smad2 & MMP-8 \\
\hline Group 1 (old subjects) & $0.54 \% \pm 0.44 \%$ & $2.13 \% \pm 1.39 \%$ & $0.34 \% \pm 0.42 \%$ \\
\hline Group 2a (young subjects before UVR exposure) & $1.48 \% \pm 0.72 \%$ & $4.16 \% \pm 1.58 \%$ & $0.00 \% \pm 0.00 \%$ \\
\hline Group 2b (young subjects after UVR exposure) & $0.48 \% \pm 0.51 \%$ & $1.81 \% \pm 1.16 \%$ & $1.36 \% \pm 0.68 \%$ \\
\hline P value & $<0.003^{1}$ & $<0.002^{1}$ & $<0.001^{1}$ \\
& $<0.003^{2}$ & $<0.008^{2}$ & $<0.03^{2}$ \\
& $=0.81^{3}$ & $=0.58^{3}$ & $<0.0013$ \\
\hline
\end{tabular}

The proportions of cells with TGF- $\beta 1$, Smad 2 or MMP- 8 immunoreactivity were measured as described in Material and methods. Values represent mean \pm SD. P values refer to the following groups: ${ }^{1}$ Between Groups $2 \mathrm{a}$ and $2 \mathrm{~b} ;{ }^{2}$ Between Groups $2 \mathrm{a}$ and $1 ;{ }^{3}$ Between Groups $2 \mathrm{~b}$ and 1. Abbreviations: MMP-8 - matrix metalloproteinase 8; TGF- $\beta 1$ - transforming growth factor beta 1; UVR - ultraviolet radiation

$(\mathrm{p}<0.03)$. There was a statistically significant difference between Groups 1 and $2 b(\mathrm{p}<0.01)$ (Table 1).

We found a positive correlation between TGF- $\beta 1$ expression and the number of Smad2 + cells in Groups $2 \mathrm{a}$ and $2 \mathrm{~b}(\mathrm{r}=0.66, \mathrm{p}<0.04 ; \mathrm{r}=0.74, \mathrm{p}<0.02$; respectively), however, there was no correlation between TGF- $\beta 1$ and MMP- 8 expression. We did not find any correlations between immunoreactivity of the studied proteins in Group 1 (Table 2). 
Table 2. Spearman rank-order correlations between the immunoexpression of TGF- $\beta 1$, Smad 2 and MMP- 8 proteins in skin biopsies

\begin{tabular}{|l|c|c|c|}
\hline Pair of variables & $\begin{array}{c}\text { Group 1 } \\
(\mathbf{n}=\mathbf{1 5})\end{array}$ & $\begin{array}{c}\text { Group 2a } \\
(\mathbf{n}=\mathbf{1 5})\end{array}$ & $\begin{array}{c}\text { Group 2b } \\
(\mathbf{n}=\mathbf{1 5})\end{array}$ \\
\hline TGF- $\beta 1$ and Smad2 & $\mathrm{r}=0.54$ & $\mathrm{r}=0.66$ & $\mathrm{r}=0.74$ \\
\hline & $\mathrm{p}=0.10$ & $\mathrm{p}<0.04$ & $\mathrm{p}<0.02$ \\
\hline TGF- $\beta 1$ and MMP-8 & $\mathrm{r}=0.1$ & - & $\mathrm{r}=-0.19$ \\
\hline & $\mathrm{p}=0.78$ & & $\mathrm{p}=0.59$ \\
\hline
\end{tabular}

Groups and abbreviations were defined as described in Table 1

\section{Discussion}

Ultraviolet radiation is an environmental factor that may cause DNA damage, leading to the generation of genetic mutations and the development of skin cancer. It is also known revealed that UVR can activate various growth factors and cytokine receptors on the surface of cells [9-11]. The consequence of this phenomenon is the activation of various intercellular signaling pathways, induction, and the activation of transcriptional factors, especially protein -1 and NF- $\kappa \mathrm{B}$, and changes in gene transcription [10, 12-14]. In spite of the many publications on the mechanisms of UVR, there are only scarce data on its influence on the activation of TGF $-\beta$ receptors and the TGF/Smad signaling pathway. Hanet et al. [15] showed that UVR causes a decrease in the expression of TbRII receptor and the induction of Smad7 protein, which leads to diminished expression of TGF- $\beta$ and Smad2. These molecular mechanisms seem to be very important in the development of photocancerogenesis, due to the fact that TGF- $\beta$ is strongly involved in the synthesis of collagen [16]. Quan et al. [17] showed in vitro that the TGF- $\beta /$ Smad/CTGF/procollagen pathway is involved in aging. They also showed the decreased expression of these proteins in human skin with symptoms of aging.

In extrinsic aging (i.e., photoaging), analogue mechanisms related to the TGF- $\beta /$ Smad 2 pathway dysregulation are observed [18]. Literature data confirm the ability of UVR to disturb this signaling pathway via decreased expression of TGF- $\beta$ type- 2 receptor. This phenomenon leads to changes in the expression of genes encoding procollagen 1 [19]. Ultraviolet radiation activates cytokines and growth factors, and also disturbs the TGF- $\beta /$ Smad signaling pathway. This results from the reduced expression of TbRII receptor and the induction of Smad7 proteins, leading in consequence to the inhibition of the TGF- $\beta / \operatorname{Smad} 2 / 3$ pathway, its translocation to the nucleus, and the generation of the Smad/DNA complex [20-21]. These data are in line with our observations. In our study, we showed a statistically significant decrease in the expression of both TGF- $\beta$ and Smad 2 in the skin of young people exposed to acute doses of natural UVR, as well as in the skin of the elderly people whose skin showed multiple clinical signs of photodamage. The lack of statistical differences between these two groups of volunteers testifies for the dysregulation of the TGF- $\beta / \mathrm{Smad}$ molecular pathway in the skin of young healthy people under short exposure to UVR. This observation probably enables us to assess this phenomenon as an early biomarker of photoaging. On the other hand, the decreased expression of TGF- $\beta /$ Smad 2 in people with photodamaged skin (high cumulative UVR dose over the whole life), who has not been exposed to acute UVR within the past several months before the biopsy, proves the lack of photoadaptive mechanism and allows us to assess these proteins as a persistent biomarker of photoaging.

Histological and ultrastructural examinations of skin damaged by exposure to UVR showed many characteristic processes localized in the dermis. Among the most important of these were the disorganization of collagen fibers, the decreased amount of collagen I and III precursors, and elastin deposits. These phenomena result from the increased activity of metalloproteinases induced under UVR. Current knowledge suggests that thus is the key pathogenic mechanism involved in photoaging. In various studies [21-24], it has been shown that exposure of skin to UVR induces epidermal expression of three main metalloproteinases - namely, collagenase, gelatinase, and stromelysin. These proteins are translocated through the basement membrane zone to the dermis and degrade collagen [16]. Simultaneous dysregulation of adhesive proteins, including laminin, leads to the destruction of the dermal-epidermal junction [4]. Enhanced expression of MMPs and decreased amount of collagen IV result in degradation of dermal-epidermal junction. It alters epidermal integrity, its impaired nutrition and influx of inflammatory cells. All the changes observed in epidermis of photodamaged skin result from UVR mediated dermal changes in extracellular matrix [25].

The literature contains consistent data on the very low expression of all MMPS, apart from MMP-14, in healthy human skin with no symptoms of photoaging. Our results are in line with these observations, as in the group of young people in whom skin biopsies were taken before UVR exposure, the expression of MMP-8 was not detected at all.

MMP-8 (neutrophil collagenase) is activated in the skin subsequent to the activation of neutrophils mediated by UVR. The increase in the expression 
of MMP-8 after six days' exposure to UVR was confirmed by the literature data [20].

UVR causes changes in collagen via the degradation and disorganization of collagen fibers, as well as through the inhibition of its synthesis. A single exposure of the skin to UV (2 MED) leads to the inhibition of procollagen synthesis within $24 \mathrm{~h}$, which is followed by an increase in its synthesis after $48-72 \mathrm{~h}$. This phenomenon is also linked with the impairment of the TGF- $\beta$ pathway. Collagen degradation, on the other hand, mainly results from metalloproteinase activation [1].

\section{Conclusions}

Based on our results, we can conclude that the decrease in the expression of TGF- $\beta / \mathrm{Smad} 2$ is a persistent biomarker of photoaging, while the increase in the expression of MMP-8 is marker of acute sun exposure.

\section{Acknowledgments}

This study was funded by the National Center of Science, grant No. 2012/05/B/NZ5/01885 and by EC Framework 7 Program under contract No. 227020, "The Impact of Climate and Environmental Factors on Personal Ultraviolet Radiation Exposure and $\mathrm{Hu}$ man Health (ICEPURE)" and Medical University of Lodz project No. 503/1-152-01/503-01.

\section{References}

1. Quan T, Quin Z, Xia W et al. Matrix degrading metalloproteinases in photoaging.J Invest Dermatol. 2009;14:20-24. doi: 10.1038/jidsymp.2009.8.

2. Ai F, Zhang X, Li X et al. Up-regulation of matrix metalloproteinases in a mouse model of chemically induced colitis-associated cancer: the role of microRNAs. Oncotarget. 2015;6:5412-5425. PMID: 25742789.

3. Xia W, Quan T, Hammerberg C et al. A mouse model of skin aging: Fragmentation of dermal collagen fibrils and reduced fibroblast spreading due to expression of human matrix metalloproteinase-1. J Dermatol Sci. 2015;78:79-82. doi: 10.1016/j.jdermsci.2015.01.009.

4. Van Doren SR. Matrix metalloproteinase interactions with collagen and elastin. Matrix Bio. 2015;44-46:224-231. doi: 10.1016/j.matbio.2015.01.005.

5. Oshimori N, Oristian D, Fuchs E. TGF- $\beta$ promotes heterogeneity and drug resistance in squamous cell carcinoma. Cell. 2015;160:963-976. doi: 10.1016/j.cell.2015.01.043.

6. Sedda S, Marafini I, Dinallo V et al. The TGF- $\beta /$ Smad System in IBD Pathogenesis. Inflamm Bowel Dis. 2015;21:2921-2925. doi: 10.1097/MIB.0000000000000542.

7. Akhurst RJ, Padgett RW. Matters of context guide future research in TGF $\beta$ superfamily signaling. Sci Signal. 2015;8:re10. doi: 10.1126/scisignal.aad0416.

8. Piek E, Westermark U, Kastemar M et al. Expression of transforming-growth-factor (TGF)-beta receptors and Smad proteins in glioblastoma cell lines with distinct responses to TGF-beta1. Int J Cancer. 1999;80:756-763. PMID: 10048979.

9. Muthusamy V, Piva TJ. A comparative study of UV-induced cell signalling pathways in human keratinocyte-derived cell lines. Arch Dermatol Res. 2013;305:817-833. doi: 10.1007/s00403-013-1412-z.

10. Salucci S, Burattini S, Curzi D et al. Antioxidants in the prevention of UVB-induced keratinocyte apoptosis.J Photochem Photobiol B. 2014;141:1-9. doi: 10.1016/j.jphotobiol.2014.09.004.

11. Müller I, Beissert S, Kulms D. Anti-apoptotic NF- $\kappa$ B and "gain of function" mutp53 in concert act pro-apoptotic in response to UVB + IL-1 via enhanced TNF production. J Invest Dermatol. 2015;135:851-860. doi: 10.1038/jid.2014.481.

12. Koch-Paiz CA, Amundson SA, Bittner ML, Meltzer PS, Fornace AJ Jr. Functional genomics of UV radiation responses in human cells. Mutat Res. 2004;549:65-78. PMID: 15120963.

13. Lee H, Morales LD, Slaga TJ et al. Activation of T-cell protein tyrosine phosphatase suppresses keratinocyte survival and proliferation following UVB irradiation. J Biol Chem. 2015;290:13-24. doi: 10.1074/jbc.M114.611681.

14. Han KH, Choi HR, Won CH et al. Alteration of the TGF-beta/ /SMAD pathway in intrinsically and UV-induced skin aging. Mech Ageing Dev. 2005;126:560-567. PMID: 15811425.

15. Maroni D, Davis JS. Transforming growth factor Beta 1 stimulates profibrotic activities of luteal fibroblasts in cows. Biol Reprod. 2012;87:127. doi: 10.1095/biolreprod.112.100735.

16. Quan T, He T, Kang S et al. Ultraviolet irradiation alters transforming growth factor beta/smad pathway in human skin in vivo.J Invest Dermatol. 2002;119:499-506. PMID: 12190876.

17. Quan T, He T, Kang S et al. Solar ultraviolet irradiation reduces collagen in photoaged human skin by blocking transforming growth factor-beta type II receptor/Smad signaling. Am J Pathol. 2004;165:741-751. PMID: 15331399.

18. Quan T, He T, Voorhees JJ et al. Ultraviolet irradiation blocks cellular responses to transforming growth factor-beta by down-regulating its type-II receptor and inducing Smad7. J Biol Chem. 2001;276:26349-26356. PMID: 11320083.

19. Tierney EP, Hanke CW. Recent advances in combination treatments for photoaging: review of the literature. Dermatol Surg. 2010;36:829-840. doi: 10.1111/j.1524-4725.2010.01557.

20. Hwang KA, Yi BR, Choi KC. Molecular mechanisms and in vivo mouse models of skin aging associated with dermal matrix alteration. Lab Anim Res. 2011;27:1-8. doi: 10.5625/lar.2011.27.1.1.

21. Sandby-Møller J, Thieden E, Philipsen PA et al. Skin autofluorescence as a biological UVR dosimeter. Photodermatol Photoimmunol Photomed. 2004;20:33-40. PMID: 14738531.

22. Rittié L, Fisher GJ. Natural and sun-induced aging of human skin. Cold Spring Harb Perspect Med. 2015;5:a015370. doi: 10.1101/cshperspect.a015370.

23. Rabe JH, Mamelak AJ, McElgunn PJ et al. Photoaging: Mechanisms and repair. J Am Acad Dermatol. 2006;55:1-19. PMID: 16781287.

24. Naylor EC, Watson RE, Sherratt MJ. Molecular aspects of skin ageing. Maturitas. 2011;69:249-256 doi: 10.1016/ /j.maturitas.2011.04.011.

25. Longo C, Cesari A, Berretti F, Cesarino AM, Pellacani G. Skin aging: in vivo microscopic assessment of epidermal and dermal changes by means of confocal microscopy. J Am Acad Dematol. 2013;68:e73-82. doi: 10.1016/j.jaad.2011.08.021.

Submitted: 6 July, 2015

Accepted after reviews: 8 March, 2016 Available as AoP: 21 March, 2016 